\title{
Psicanálise: algumas contribuições para a educação
}

Sueli Soura dos Santos ${ }^{*}$

Resumo: Este trabalho visa trazer algumas contribuições teóricas da psicanálise para a educação através do estudo do psiquismo humano. Desenvolve o tema do desejo de saber que passa pela formação do sujeito do inconsciente. Para a psicanálise, segundo Freud e Lacan, o desejo está atrelado ao desejo do Outro, ou seja, quem estimula seu interesse pelas coisas do mundo. A divisão de um eu / não eu chega à criança por seu desejo de saber-se distinta do Outro, e pela linguagem e suas condições de produção de sentidos entre as palavras e as coisas, se viabiliza a capacidade de simbolização e do conhecimento.

Palavras-chave: Educação. Psicanálise. Inconsciente. Eu/não eu. Desejo.

\section{Psychoanalysis: a few contributions for the education}

\begin{abstract}
This work aims to bring some theoretical contributions from Psychoanalysis to Education through the study of the human psyche. It develops the theme of the desire of knowing that depends on the subject's unconscious formation. For psychoanalysis, according to Freud and Lacan, the desire is coupled to the desire of the Other, that is, the person who stimulates the child's interest in the things of the world. The separation of 'me' and 'not-me' derives from the child's desire to perceive them as distinct from the Other. Also, language and the child's conditions of production of meanings between words and things, allows the ability of symbolization and knowledge acquisition.
\end{abstract}

Keywords: Education. Psychoanalysis. Unconscious. Me/not-me. Desire.

\section{O Desejo de saber e a emergência do Eu}

A Lagarta e Alice olharam-se por algum tempo em silêncio... finalmente, a Lagarta tirou o narguilé da boca e perguntou, em voz lânguida e sonolenta:

- Quem é você?...

- Acho que eu mesma não posso explicar - disse Alice - porque eu não sou eu, está vendo?

- Não, não estou (CARROLL, 1980, p. 65).

A psicanálise, enquanto campo do conhecimento sobre as formações do inconsciente e do psiquismo humano, traz à luz que a razão humana não lhe dá a certeza sobre o entendimento de si. Tampouco assegura o controle sobre seus atos ou sobre a realidade. Freud, criador da psicanálise, ao formular o conceito de inconsciente, nos revela que o aforismo proposto por Descartes, "penso logo sou”, não justifica maisa racionalidade como sendo o que nos distingue e garante o conhecimento sobre si mesmo e o estar no mundo.

Ao tomar como epígrafe, um recorte do texto de Carroll, podemos pensar que o personagem de Alice nos ensina sobre as agruras do processo do crescimento e conhecimento, as angústias das

\footnotetext{
* Doutora em Educação pela Universidade Federal do Rio Grande do Sul (UFRGS). Psicanalista pelo Centro de Estudos Psicanalíticos de Porto Alegre (CEP). E-mail: suelisantos-s@hotmail.com
} 
transformações do humano em seu devir. A consciência de si, a formação de um eu, o processo de crescimento sempre nos oferece a incerteza sobre o que já supúnhamos como definido e consolidado em nosso eu, o que nos lança em um labirinto, nodesvão de nossas certezas.

Para Freud, o desenvolvimento ontogenético tem sua origem a partir dos conceitos de inconsciente e da sexualidade. Com relação ao inconsciente, o define como uma instância psíquica constituída por tendências, desejos e intensidadespulsionais, não obedecendo ao princípio de contradição, ou tempo cronológico, regulando-se pelo princípio de prazer e desprazer.

Nesta perspectiva, os processos psíquicos seriam, em si, inconscientes. No núcleo do inconsciente está o desejo sexual recalcado. O inconsciente freudiano não é a simples ausência de consciência, mas está para além disso, é fundamentalmente constituído por pulsões sexuais. Essa afirmação causoucerto estranhamento em seu tempo, pois introduz a ideia de uma sexualidade infantil como centro da vida psíquica.

A psicanálise não se ocupou especificamente da educação, ou em conceituar a educação. Não encontramos na obra de Freud ou de Lacan, autores nos quais nos apoiamos, qualquer especificidade sobre o tema da educação. No entanto, o estudo da psicanálise aponta alguns focos que iluminam os caminhos do entendimento do educar, e sobre o que fazemos na tentativa de educar.

Nosso interesse pelas vicissitudes do educar, então, nos impõe que consideremos o campo da psicanálise. No entanto, a psicanálise não nos dirá o que fazer concretamente com as crianças, mas podemos entender que a psicanálise nos diz o que não deve ser feito. Diferentemente da Psicologia da educação, que orienta ou dá conselho aos pais e professores sobre o que fazer, os limites da aprendizagem, etc., a psicanálise se preocupa em abrir questionamentos, o que se deve pensar sobre a aprendizagem.

As crianças não são adultos em miniatura, ou cópias fiéis de pais ou professores. Isso seria uma reprodução narcísica e deformada das possibilidades de um devir. Não é possível que a função do educar reproduza modelos replicantes, sem questões, sem curiosidade pelo que vê, ouve, entende, enfim, sem estranhamento.

O que a psicanálise vai nos ensinar é que a criança não repete o que ensinamos de forma linear, mas se apropria à sua maneira, pelas formações do inconsciente, o que tem a ver com a descoberta freudiana. A impossibilidade de reproduzir com exatidão uma mensagem se deve ao fato de que a comunicação humana é equívoca. À linguagem sempre cabem distorções, interpretações. É impossível compreender de forma inequívoca o que nos é dito. As dúvidas, incompreensões sobre o que nos é ensinado são reaçõesnaturais, indispensáveis e constitutivas da formação de um sujeito.

Sabemos que a sociedade se organiza a partir da reprodução de condições históricas, econômicas, políticas e ideológicas. Essas condições estão presentes nos seguimentos da família, da educação e seus produtos culturais, assim como nos sistemas de leis e no sistema religioso. Esses 
sistemas são interdependentes, abarcam a sociedade como um todo, afetando a todos, enquanto indivíduos e seres sociais. É forçoso que se conheçam a história e as contingências constitutivas da sociedade em que nos inserimos. Freud (1927) nos ensina que é preciso conhecer o passado e o presente para dar sentido a um futuro, embora nada o garanta.

O que formula Freud, em O Futuro de uma Ilusão (1927), sobre a civilização, tem um valor indiscutível na leitura do social ainda hoje. Afirma que as pessoas experimentam o presente de forma ingênua, sem qualquer reflexão do que lhes acontece em sua vida privada, como consequência de um conjunto de contingências sociais, com uma história na qual estão inseridas. Isso as aliena de suas próprias implicações enquanto sujeitos históricos.

Quando não há um distanciamento crítico do passado, quando não damos importância à história que nos constituiu, é difícil ter discernimento sobre a construção do futuro. Tomando a palavra de Jessé Souza:

Não se pode, afinal, ensinar aquilo que não se aprendeu. Veem-se as mães preocupadas com a escola do filho, mas como elas sabem que a escola não fez diferença para si própriase para um filho, exemplos são muito mais importantes que as palavras ditas, não percebem efetivamente como ela pode fazer a diferença para eles (SOUZA, 2016, p. 63).

Não é o mesmo a ação de educar. A ação de educartem por princípio treinar, formatar, padronizar, normatizar alguns padrões de comportamento, que correspondam a um conjunto de expectativas ouum modelo aceitável para a convivência de um grupo social de pertencimento. Isso não corresponde ao que se entende por educar.

Educar é outra coisa. Educar é criar condições de despertar o desejo de saber, ou, como pensamos em psicanálise, a inscrição da pulsão epistemofílica. Para que o educar ocorra, é necessário que se deem algumas condições de possibilidades.

Sem o desenvolvimento de um eu, ou seja, para que se estabeleçam condições de subjetivação, para que aí se possa nomear um eu que se reconheça como tal, se faz necessária a inserção de uma inscrição no desejo de um outro, um Outro. Não se pode mais ignorar que, para que haja possibilidade de aprendizagem, para que haja condições de investimento pelas coisas do mundo, é necessário que o psiquismo seja despertado pelo que interessa ao Outro.

Quando usamos aqui o Outro, com maiúscula, se trata de um conceito da psicanálise que representa o ideal, aquele que supomos modelo. Objeto desejado como sendo sem falhas, que, em princípio, está referido às figuras parentais. É a partir dessa valorização dos objetos, como algo que parece especial, que o bebê passará a se interessar, para que ele próprio passe a ser objeto de desejo dos pais. Assim, se rompe a barreira da completude, abrindo espaço para a diferenciação, a alteridade.

Pensemos no que nos propõe Lacan sobre seu conceito de estádio do espelho. A transição de um estado indiferenciado, fusional, para um não eu, marca que algo está para além, algo que falta ao 
bebê. O que o inscreverá como ser faltante, além disso, é que um terceiro, um Outro, que pode ser o pai ou quem cumpre essa função, delimita a impossibilidade da fusão narcísica de completude mãe/bebê.

Essa ruptura se inscreve como rompimento narcísico, afinal o bebê não será, como já dissemos anteriormente, um replicante, uma cópia fiel de seus pais. Ao adentrar no processo da linguagem terá que começar a dar algo, palavras, o que definitivamente funda a possibilidade de pensar, interrogar, tentar dar conta da clássica interrogação Che vuoi:O que queres? Qual é teu desejo? Rompido o espelho, a próxima questão será: se não somos um, o que eu sou?

Aí podemos situar o desejo de saber e a emergência do Eu. Voltando ao recorte da angústia de saber de si, Alice não sabe como se explicar diante dalagarta: “- Acho que eu mesma não posso explicardisse Alice - porque eu não sou eu, está vendo?” (CARROLL, 1980, p. 65). Alice, nessa ficção literária, também espera que um Outro, a lagarta, a veja e diga o que vê nela, haja vista que nem ela sabe de si. A menina espera que a lagarta, que faz as perguntas, tenha todas as respostas. Por isso se chama Absolei, ou seja, absoluta, pois sabe de tudo. Sendo assim, quem sabe lhe dê uma imagem de existência. Mas só Alice poderá descobrir quem é.

\section{Do sujeito epistêmico a um sujeito do Desejo}

Alice não sabe dizer de si. Mas quem de nós pode ou sabe dizer? Quando interpelados a falar de nós mesmos, o máximo que conseguimos é dar algumas atribuições, algumas características que supomos nos representar, ou identificar, mas o eu mesmo, não sabemos como defini-lo. Qual unidade nos constitui? Qual matriz desejante forja o que podemos vir a ser? Dizendo de outra forma, não é possível ter garantias ou saber se aquilo que os pais desejaram quando geraram um filho, veio a se concretizar. No entanto há uma antecipação impossível de um desejo de completude implicando o sujeito em devir, um vir a ser.

Mas este objeto de desejo não vai receber nenhum tipo de código, protocolo ou padrão genético que oriente como realizar o desejo dos pais. Não há como passar essa informação ou comunicação sem atropelos ou mensagens enigmáticas. O homem é o único ser que não repete com exatidão uma mensagem. A psicopatologia na infância, assim como a possibilidade de apreensão das coisas e saberes do mundo, é como um curto-circuito da comunicação dos adultos com as crianças.

Se, entre adultos, não sabemos como aquele que nos escutairá processar aquilo que dizemos, imagine com quais dificuldades uma criança enfrentará aquilo que osadultos, tentam lhe transmitir.A comunicação humana, para a psicanálise, não é como a dos animais, ou seja, não é passível de reprodução sem que muitas questões intervenham desde sua imprecisão. 
Um exemplo sobre a imprecisão da comunicação humana: quando solicitamos que cinco crianças, após ouvir uma história, desenhem o personagem principal, e nos contem porque ele é o principal, seguramente, vamos encontrar nos desenhos de criançasdiferentes, personagens diferentes;e mesmo que o personagem seja escolhido de forma unânime,os motivos das escolhas e as representações, desse personagem principal, serão diversos. Cada criança escolherá, por motivos muito particulares, seu personagem, e sua justificativa será igualmente particular.

Mas se, arbitrariamente, determinarmos que tal ou qual personagem da história que contamos é o principal, as crianças desenharão de acordo com sua imaginação, com sua fantasia. Mesmo que o livro de história exiba uma gravura modelo, o personagem será desenhado por cada criança de forma bem diferente do modelo.

Suas associações sobre o porquê da importância do personagem desenhado poderão ser justificadas com uma história totalmente outrade seu próprio universo. Poderá recorrer a coisas que ouviu em casa ou viu na televisão, ou discutirá com um colega sobre a importância de um detalhe qualquer que, para nós, não pareça fazer nenhum sentido ou seja irrelevante à história contada.

Não só a linguagem é equívoca, porque polissêmica, mas também porque possibilita uma multiplicidade de interpretações e percepções. O inconsciente de cada um constrói suas próprias redes significantes, por isso são diversas. As formas de subjetivação de cada pessoa são construídas ao longo de sua história, com suas particularidades. Ainda mais na infância, quando os limites entre o real e o imaginário são tão tênues. No entanto, estamos sempre procurando entender, e corresponder àquilo que supomos ser o que um outro espera de nós.

Finalmente, como ser alguém interessante para um adulto? Para Freud, o lugar que os pais ocupam na infância do indivíduo, é de onde o sujeito se forma. Aquilo que marcou cada um na própria infância. Então, como realizar um desejo ou ser o desejo de um Outro, quando não se tem a certeza do que se inscreveu como marca de desejo?

À medida que o psiquismo humano vai sendo constituído, através da relação com as figuras referenciais, pai e mãe, ou quem exerce essa função, a criança vai se espelhar nesses objetos amorosos, buscando ser aquilo que supõe ser o desejo dos pais, ou de quem ocupa essa função. Essa busca em corresponder ao objeto de desejo dos pais ou cuidadores, será transferida mais tarde para as figuras dos professores, ouna relação com colegas, de pessoas significativas de seu mundo de convivência.

O encontro amoroso, portanto, desde o começo, exige que haja respeito e aceitação pelas possibilidades de a criança responder às nossas demandas. Há um limite para isso, qual seja: quando falamos em responder, não é o mesmo que dizer que a criança deva corresponder àquilo que gostaríamos que ela fosse, porque ela é apenas o que é, o que pode ser. Então, cada um vai entender e conhecer o outro, pelo que é, e não pelo que supomos ou desejamos que possa vir a ser.

A psicanálise nos diz: é preciso ser sincero com você mesmo, desconfiar das certezas, portanto o que é proibido é o que está no acesso da educação, ou seja, não há nada errado com a criança que não 
entende, que não aprende. A educação deve se perguntar é o que você, ou cada um, quer com o que está fazendo. O proibido é proibir que a criança não saiba, que se equivoque, que erre, que tenha dúvida. Afinal, o mundo da ciência só avançou porque duvidava, porque seus resultados sempre deixavam rastros de incertezas.

O fim da pedagogia, ou da educação, ou da escola, não é salvar o outro da ignorância, do fracasso escolar. A psicanálise nos ensina que, aocontráriodisso, o que deve interrogar a educação é como cada um deve ser interpelado enquantosujeito, como singularidade, respeitado em suas potencialidades. O educador também precisa aprender com a criança que não aprende, que não entende. A psicanálise nos ensina a perguntar: oque ele, o educador, deixou de entender sobre as necessidades dessa criança?

A diferença em cada criança não é apenas decorrente de alguma limitação de adaptação a um padrão a ser atingido de desenvolvimento. Isso porque, o inconsciente, conceito psicanalítico formulado por Freud, está presente em qualquer psiquismo, independente de suas condições cognitivas. O inconsciente se expressaem cada gesto, ato falho, sonho, está na ponta da língua, entre a realidade do sexual e a linguagem se manifestando pela palavra.

Faço aqui uma observação que me parece fundamental para explicitar o que se entende por sexual. Para a psicanálise, sexual é toda busca de prazer associado a uma fantasia. Portanto, não se trata de genitalidade, embora não a descarte também.

Por exemplo, quando cuidamos de um bebê, na intimidade da amamentação ou no cuidado com a higiene, o toque em seu corpo, o conforto produzido pela saciedade da alimentação em contato com o corpo da mãe, com seu sussurro, as palavras que são oferecidas com o leite, ou no trocar de fraldas, na limpeza dos genitaisou no banho, todoo corpo da criança é despertado pelo toque e as palavras da mãe, pelo carinho que desperta o corpo erógeno.

Ou seja, o corpo do bebê é erotizado, despertado, descoberto como algo que, por esse cuidado, produz satisfação para ele e para a mamãe. A isso chamamos sexual, e, através desse despertar erógeno marcadono corpo, o bebê se ligará a esse Outro, a mãe ou quem exerça essa função. É pela repetição da experiência de satisfação que o bebê encontrará o desejo de repetir a experiência, que começará a balbuciar sons que ouve da mãe.

Dizendo de outra forma, a mãe vai emprestando palavras para dar sentido ao que ela sente, ao que o bebê sente. Ele, o bebê, será dessa forma definitivamente imerso no mundo da linguagem, mesmo que leve muito tempo para ligar as palavras às coisas e sentimentos. É pela palavra que o bebê despertará o desejo de nomear o mundo, de entrar no mundo do Outro.

Ora, a ferramenta da educação é a palavra. Portanto, a palavra do adulto, endereçada à criança, é o que a educa. Dizendo de outra forma, a educação tem a ver com fazer marcas. Resta saber que marcas queremos fazer. Sabemos que essas marcas têm suas formas ideológicas que não dão nenhuma 
garantia, nem de um projeto definido, nem de um objetivo que unifique tantos indivíduos em suas diferenças de desenvolvimento ou em suasexperiências e condições sociais.

Isso me faz lembrar uma experiência em escola infantil com crianças cegas, quando fazia observação, buscando subsídios, para minha tese de doutorado. Eu observava uma turma de crianças entre cinco e seis anos que aprendiam a noção das cores. Um dos conteúdos, determinados institucionalmente a ser desenvolvido, era o estudo das cores. Um programa hegemônico, sem considerar a possibilidade das diferenças entre crianças videntes ou cegas, ouvintes ou surdas, ou com qualquer tipo de necessidade de aprendizagem especial. Esse tema, as cores, tinha que ser desenvolvido. Mas como o fazer, não havia qualquer especificidade.

Perguntei à professora: com que objetivo ensinava as cores para crianças cegas? Ela me explicou que era importante porque associando a ideia de amarelo ao sol, o azul ao céu, o verde às folhas das árvores, e por aí vai, a criança poderia entender as cores. Assim entenderia que as coisas têm uma cor, e isso a ajudaria a ligar essa ideia aos objetos. Justificava: por exemplo, ao saber sobre as cores, poderia fazer combinaçõesdas cores na escolha das roupas, imaginar como eram os objetos do mundo, entre tantas outras possibilidades.

Além do mais, não deveria haver diferença entre o que se ensinava àscrianças cegas ou videntes, embora essa turma fosse de crianças cegas e com deficiência visual bastante grave.Perguntei então: qual era mesmo a cor do sol, do céu, das folhas. Singelamente me respondeu que o sol era amarelo. Porque era quente a criança saberia que quando estivesse no calor havia sol, que amarelo era uma cor quente, e seguiu seu mito de aquarela do mundo. Entusiasta de sua didática e forma de ver e conhecer as cores, os elementos da natureza, parecia acreditar que o que ensinava aos estudantes correspondia à realidade. E acreditava que se fazia entender.

Não tenho muita certeza de que aquelas crianças cegas entendiam o que sua dedicada professora tentava lhes passar sobre cores e tudo o mais. Mas essa esteriotipia de compreensão metodológica, que todas as crianças devam aprender os mesmos conteúdos e da mesma forma, sejam crianças cegas ou videntes, é bastante intrigante.

Mais lamentável ainda é acreditar que essa sua teoria sobre as cores é a coisa em si, sem nenhuma ligação com os estudos dos elementos da física ou da química, que as cores são uma convenção classificatória ancorada nesses saberes, e mais, que cada cor tem um espectro considerável de matizes que a diferencia, exatamente pelaspesquisas desses campos do conhecimento.

Além do que, como cada um vê cada cor, será resultado da produção de sua experiência muito particular, associado às suas próprias representações de cor, de palavra e de coisa. Essa professora, no entanto, parecia acreditar, honestamente, em suas teorias. Em algumlugar de sua formação isso lhe foi passado, ou ela entendeu que era assim, ou criou seu próprio método de falar sobre a importância do estudo das cores para cegos. Sem nenhuma crítica, pensava que ensinava e educava, contribuindo com o conhecimento e a vida dessas crianças. 
Minha questão não era, nem continua sendo, tão somente sobre como ensinar cores para cegos ou videntes. Mas quem sabe fosse interessante saber como as crianças enxergam o mundo? A história da arte tem muito a nos ensinar sobre como representar o mundo, e seguramente as cores primárias não definem absolutamente nada sobre o que vemos e o que nos olha. Os objetos do mundo nos olham e nos despertam algum sentimento, tensão, impressão, horror ou beleza; os objetos do mundo nos ensinam a nos interessarmos sobre o que tentamos ver, entender. E mais, os objetos do mundo nos ensinam que precisamos das palavras para dar voz à nossa percepção sobre o que se mostra à nossa experiência com o mundo.

Freud, em seu trabalho de 1937, Análise Terminável e Interminável, parte VII, fala de três profissões impossíveis, quais sejam: educar, governar e analisar. Ele diz:

Detenhamo-nos aqui por um momento para garantir ao analista que ele conta com nossa sincera simpatia nas exigências muito rigorosas a que tem de atender no desempenho de suas atividades. Quase parece como se a análise fosse a terceira daquelas profissões impossíveis quanto às quais de antemão se pode estar seguro de chegar a resultados insatisfatórios. As outras duas, conhecidas há muito mais tempo, são a educação e o governo (FREUD, 1937, p. 265).

Por que impossíveis? Porque não controlamos os efeitos da nossa fala. Porque no inconsciente se produzem sentidos, tanto no psiquismo dos adultos como das crianças. Como endereçamos a palavra, quando ensinamos,será influenciado pelos recursos inconscientes da comunicação entre o professor e o aluno. Não há paridade entre o que é ensinado e o que será processado, compreendido pelo estudante.Compreender as coisas do mundo e do conhecimento necessita a passagem por rituais que já estão dados a cada um, antes da formação de um eu, que antecede o ser.

Dizendo de outra forma, o mundo já está aí antes que tenhamos nascido, e seguirá existindo depois que não estivermos mais aí. A criança chega ao mundo depois de muitas realizações, conquistas e saberes.Quanto a si mesma, não tem como saber se foi concebida de forma natural ou depois de longo processo de fertilização assistida, ou se foi adotada. A criança não sabe de todo o processo de espera e das condições de seus pais para tal ato. Mas ao chegar nessa família, nesse lar, é festejada e não tem nenhuma noção desse momento de comemoração.

A festa por seu nascimento, de sua inclusão em uma comunidade familiar, não significa minimamentenada para o bebê, o qual não sabe porque todo aquele barulho. Será preciso algum ou muito tempo para que ele discrimine ruídos, borrões, sensações desagradáveis e agradáveis, de sons de voz da mãe, do pai, de outras pessoas, de música, de fala eque a fala quer dizer alguma coisa. Ele precisará de tempo para discriminar borrões de formas, cores, rostos. Os adultos precisarão falar para explicar do que se trata a vida, os objetos, os sentimentos.

A experiência só se ordena pela palavra, e pelo sentido que vai se construindo dela.Ao contrário, quando se acredita que educar passa pela normatização de conteúdos do conhecimento, pela 
intolerância à diferença, pela violência, pela punição, pelo castigocomo recurso disciplinar, como exemplo que instalará o medo, a repressão, a palavra aí perdeu suas coordenadas. Isso é o oposto da palavra que espera gerar sentidos educativos. Os métodos educativos precisam contemplar a diversidade, e aprender que essa diversidade interpela o que a educação ignora.

Voltando à situação da educação, aprendemos com a psicanálise que, não é porque uma criança,em um grupo de estudantes, não fala ounão enxerga, ou não escuta, ou tem alguma dificuldade em função de alguma síndrome, que necessariamente tem uma inibição ou trauma. Ou, ao contrário, deva ser obrigada a falar ou constrangida a se expor, como forma de vencer ou dessensibilizar seus medos. Talvez essa criançatenha um tempo diferente de seu grupo, seu próprio tempo para decodificar a experiência que lhe é apresentada.

Crianças quietas, observadoras, que não respondem imediatamente por meio da palavra ou via motora, podem nos dar outros tipos de resposta. Seu olhar nos observa ou se distancia no horizonte, mas isso pode ser um retorno de reflexão, de associações com outras experiências. É importante que o educador esteja atento a essas manifestações de contato com o mundo interior da criança, com ligações que necessariamente não têm uma resposta na ponta da língua, mas que se possa pensar que o professor está implicado nessa observação.

Porvezes não entendemos que há interesse no que o professor diz, apesar do silêncio espectador de uma criança. Será que não podemos esperar que cada um tenha um tipo de compreensão, pois o que dizemos ou ensinamos produz vários sentidos? Qual o desejo do professor que move o seu ensinar? Qual o desejo do aluno que move sua atenção?

Freud nos ensina que a educação vai nos preparar para a realidade impossível do desejo. Ou seja, em psicanálise, o desejo é da ordem do irrealizável, do inominável. Diferente da pedagogia que associa desejo à fantasia, à vontade. Freud nos revela que o desejo é a faísca, o que dispara, o que desajusta o homem consigo mesmo, por isso quer poder ser diverso daquilo que é, e que ele nem sabe o que é. No entanto na deriva dessa travessia impossível, entre o que se supõe ser e o que se busca vir a ser, nos libera para seguirmos desejantes.

As crianças se interessam pelo que supõem que seja o objeto de desejo dos pais. Certa vez um analisante, profissional respeitado na área de tecnologias em uma grande empresa de informática, contava orgulhoso que seu filho de dois anos e meio já se interessava em pegar e mexer em seu celular, como se aí já se esboçasse um gênio das tecnologias ou algo do gênero. Equivocadamente não percebia que seu filho se interessava pelo objeto do qual o pai não tirava os olhos e as mãos, mesmo com seu filho no colo, em qualquer momento em que estivessem juntos.

As crianças se interessam pelo mundo dos adultos, pelo que os adultos dão de testemunho de seu interesse, de seu desejo. Custamos aentender que as crianças nos observam e tentam identificar o que é o centro de atenção de nosso olhar, de nosso discurso. Para as crianças, pegar canetas, celulares, batons, gravatas, diz de seu interesse não de gênero, mas pelo que aos pais interessa. Se não falamos 
sobre nossos interesses, e que elas, as crianças, fazem parte de nosso interesse, as crianças ficam sem norte.

A palavra é o que orienta, é uma guia para a criança, para que ela possa nomear os objetos do mundo e os objetos que lhe interessam, ou o que teme, o que a assusta ou a deixainfeliz. Mas, se não estamos convictos ou inteiros nessa relação, a criança não respeita o valor da palavra.

\section{Desenvolvimento ou constituição do sujeito (do desejo)}

Para Recalcati (2016, p. 115): “A verdadeira liberdade implica, antes, o vínculo com o Outro como aquilo que abre minha vida à incógnita ingovernável do desejo". Isso significa que estamos falando de um desejo inominável, pois atribuído a uma demanda suposta a um Outro. Não se trata aqui de um sujeito/indivíduo ou pessoa; falamos do sujeito do inconsciente, sujeitado ao inconsciente.

Esse é o inconsciente que Freud nos ensinou, forjado e imerso no mundo da linguagem desde seu estudo $A$ interpretação das Afasias (1891). Um texto revolucionárioa seu tempo, pois esboça o embrião de todo o seu desenvolvimento posterior, que leva ao estudo dos lapsos, do ato falho, do chiste, do sonho, que estão implicados no estudo das pulsões. Portanto está para além da questão neurológica, sendo a interpretação das Afasias um estudo mais estrutural do psiquismo do que neurológico.

As observações de Freud, sobre o psiquismo humano apontam para a constituição que vai sendo forjada através das possibilidades limitadas e pré-maturas de um corpo que vem ao mundo com a precariedade biológica do bebê humano. A própria imaturidade neurológica, motora e perceptiva impõe a esse bebê cuidados e manipulações que vão despertando para um mundo externo a sua experiência caótica de realidade própria.

Através dos cuidados maternos, ou de quem cumpre essa função, o sujeito vai se constituindo, posto que não existe a possibilidade de vida humana sem a presença do Outro. O que um bebê humano conhece de seu corpo, originalmente, é apenas uma fonte contínua de sensações vividas com estranheza. Um caos a que Lacan (1998) nomeia como a angústia do corpo despedaçado, invadido por todos os lados, sem bordas em princípio, ultrapassando o orgânico, que precede a experiência unificadora do espelho.

A experiência de sua observação no espelho, sustentado pela figura materna, dá ao bebê a unificação de uma imagem de si, fundida no braço/abraço, que o sustenta. Fundindo essas duas imagens em uma só, se rompe o desamparo absoluto da fragmentação.

Cabe ao Outro responder ao grito lançado pelo bebê ao se sentir em total desamparo. A resposta a esse grito vai marcar a tradução significante do grito como chamado. Uma resposta do Outro 
faz a conexão entre dois mundos, do eu e do não eu. Aquele que atende ao chamado, ao grito de angústia, inscreve no corpo pulsional que algo existe para além do eu. Esse encontroentre o bebê e aquele que atende a seu chamado, estabelece que o bebê precisa dar algo de si como contrapartida.

Voltando a Freud (1895), em seu Projeto para uma Psicologia Cientifica, o autor postula que a primeira experiência de satisfação é mítica e o sujeito tentará em vão reconstituí-la. Essa tentativa de reconstituição é decorrente do desejo em relação à Coisa, o Isso em alemão “das Es", que não pode ser nomeado. A Coisa é dada no campo escópico, ou seja, a pulsão do olhar. É ela que confere a lei do desejo. $\mathrm{Na}$ visão da psicanálise, o desejo indestrutível se apresenta como esse abismo infinito do inalcançável que opera por deslizamento, em um plano de contiguidade, remetendo o sujeito sempre a uma falta.

Como dissemos anteriormente, a demanda do Outro, o lugar ocupado em um primeiro momento pela mãe, impõe ao bebê a questão: O que queres? Che vnoi? Como responder a uma demanda desse Outro, quando não se entende ainda qual é a questão colocada. Que deseja o objeto causa de desejo (a)? Quem sabe possamos demarcar aí as primeiras inscrições do interesse sobre o conhecimento?

Quando a mãe apresenta algo ao bebê, como, por exemplo, um chocalho, o que desperta interesse por esse objeto não está nesse objeto em si. Mas por ser apresentado pela mãe, seguido de uma série de sons indiscriminados, posto que a tal objeto vêm associadas palavras pronunciadas com alguma intensidade, o bebê percebe que algo aí brilha.

Ou seja, o objeto tem um brilho, algo que interessa àmãe e que ele, o bebê, consequentemente deve se interessar também. Mas o quê? Será por acaso o ruído do objeto?A cor, a forma?A oferta de um objeto de desejo pela mãe cria, de certa forma, o desejo pelo conhecimento do objeto.

Aprender então se aprende. Melhor dizendo, é preciso aprender a aprender. Aprender a olhar, a ouvir, a falar, a calar, a eleger, a renunciar, a esperar. O que interessa a quem oferece um estímulo, um objeto, uma história, uma música, uma palavra, será determinante para despertar o desejo de saber.

Cada vez que a mãe, ou quem cuida da criança, ou um educador oferece algo de forma interessada, um objeto de desejo, um conhecimento de forma investida libidinalmente, isso se torna interessante, não por si, mas porque oferecido por quem é especial para a criança. Quem oferece o conhecimento sobre um objeto está implicado no resultado da possibilidade de conhecer, de aprender.

Então a educação não começa necessariamente na escola, ou no sistema de aprendizagem. Educar está ligado atavicamente ao interesse amoroso por cada descoberta feita pela criança, sustentada pelo braço amoroso que envolve o mundo oferecido à criança. Isso é um pouco diferente das teorias de aprendizagem, pois não se trata apenas das possibilidades cognitivas, da capacidade de concentração, orientação, motricidade entre tantas outras condições para a prontidão ao conhecimento. Não se trata de índices de inteligência, memória, atenção, reprodução ou relações e distinção entre objetos do mundo. 
Para a psicanálise, o que desperta a criança para o mundo das coisas e do conhecimento é o objeto causa de desejo, apresentado como um significante, o que Lacan designa como objeto (a). Lacan, como profundo estudioso da obra de Freud, propõe o retorno ao estudo de seus textos, posto que é ele quem vai nos oferecer um saber que não cansa de se questionar. Freud, ao contrário do que popularmente se costuma dizer, não explica nada.

Freud pergunta, se inquieta, duvida, refaz seu pensamento incansavelmente, buscando a verdade do inconsciente, ou seja, sempre há outro dizer sobre aquilo que se diz. O inconsciente é um saber que não se sabe. Ao contrário, o inconsciente se insinua, se dá a ver nos desvãos de suas manifestações, ou seja, no interdito, no subliminar, no silêncio, no lapso, no equívoco, no esquecimento, no ato falho, no sonho, no sintoma.

Finalizo esta reflexão com o auxílio de Lacan (1969, p. 335), que nos ensina: "A produção do saber como saber distingue-se por ser um meio de produção, e não apenas de trabalho, da verdade. É nesse sentido que o saber produz o que designo pelo nome de objeto $a$ ".

Ou seja, existe em algum lugar uma verdade que não se sabe, sendo aquela que se articula no nível do inconsciente. É lá que nós devemos encontrar a verdade sobre um saber e que não se pode nomear. Esse inominável provoca o desejo de saber, de buscar a impossível completude do conhecimento, a verdade definitiva sobre o que não se sabe.

\section{Referências}

CARROLL, Lewis. Conselhos de uma lagarta. In: CARROLL, Lewis. Aventuras de Alice no País das Maravilhas. São Paulo: Summus, 1980.

FREUD, Sigmund. A interpretação das Afasias. São Paulo: Martins Fontes, 1977. (Trabalho originalmente publicado em 1891).

. Projeto para uma Psicologia Científica. In: - Obras psicológicas completas. Rio de Janeiro: Imago 1987. (Edição Standard Brasileira, 1). (Trabalho originalmente publicado em 1950 [1895]).

. Futuro de uma ilusão. In: . Obras psicológicas completas. Rio de Janeiro: Imago, 1987. (Edição Standard Brasileira, 21). (Trabalho originalmente publicado em 1927).

. Análise terminável e interminável. In: Obras psicológicas completas. Rio de Janeiro: Imago,1987. (Edição Standard Brasileira, 23). (Trabalho originalmente publicado em 1937).

LACAN, Jacques. O estádio do espelho como formador da função do eu. In: . Escritos. Rio de Janeiro: Jorge Zahar, 1998. (Trabalho originalmente publicado em 1949).

. Seminário 16: de um Outro ao outro. Rio de Janeiro: Jorge Zahar, 2008. (Trabalho

originalmente publicado em 1969). 
RECALCATI, Massimo. Não é mais como antes: elogio do perdão na vida amorosa. Rio de Janeiro: Zahar, 2016.

SOUZA, Jessé. A radiografia do golpe: entenda como e por que você foi enganado. Rio de Janeiro: Leya, 2016. 